\title{
Design for High Gain Spiral Antenna by Added Conical Cavity Wall
}

\author{
Jae-Hwan Jeong · Kyeong-Sik Min* · In-Hwan Kim
}

\begin{abstract}
This paper describes a design for a spiral antenna with a conical wall to obtain the high gain. The gain and the axial ratio of the spiral antenna were improved by a new design that included a conical wall and an optimized Archimedean slit on the ground plane in a conventional antenna with a circular cavity wall and a 4.5-turn slit. A gain improvement of $9.5 \mathrm{dBi}$ higher and a good axial ratio of $1.9 \mathrm{~dB}$ lower were measured by the added conical wall and the newly designed slit from the current distribution control on the ground plane, respectively. The measured return loss, gain and axial ratio of the proposed antenna showed a good agreement with the simulated results. The proposed antenna will be applied to a non-linear junction detector system.
\end{abstract}

Key Words: Broad Bandwidth, Circular Polarization, Conical Wall, High Gain, Metal Cap, NLJD System, NonLinear Device, Spiral Antenna.

\section{Introduction}

The electronic semi-conductor device industry has rapidly developed and become focused on minimization in recent years. Super minimal semi-conductors with high performance are frequently used for memory chips with large capacity. On occasion, these memory chips, which can contain information, have been used illegally. Accordingly, detection of hidden devices becomes difficult because of complex hiding method. Detection of a tiny chip made by the semi-conductor or the false junction material composed of a semi-conductor and a metal has been made possible by the development of a nonlinear junction detector (NLJD) [1-3].

The performance of NLJD System depends particularly on the antenna characteristics because the antenna has to satisfy broad bandwidth including transmitting frequency (Tx) and receiving frequency (Rx) band. Additionally, in order to minimize the effect of power reduction by coupled wave from the hidden device, the high gain circular polarization antenna has been mainly used for NLJD system application [4-6]. In this paper authors designed the high gain spiral antenna with novel Archimedean spiral slit on ground plane to realize the circular polarization and designed the new cavity [7] added conical wall to realize the high gain. The gain and axial ratio of spiral antenna proposed by reference
[4] had been decreased due to multi resonance characteristics. In order to solve an above problem, authors have proposed the novel spiral antenna structure that it was composed of the extended conical wall with the conventional circular cavity wall and the optimized archimedean slit conductor on the ground plane by current distribution. The resulting antenna showed a gain of 9.5 $\mathrm{dBi}$ higher than the conventional gain specification of 6 $\mathrm{dBi}$ at the interested bands.

\section{II . Antenna Design}

Fig. 1 shows an antenna configuration with a conventional 4.5-turn spiral slit structure on the ground plane [4]. A diameter of the spiral antenna is $80 \mathrm{~mm} \phi$, and an Archimedean slit $[8,9]$ is located on the ground plane. The substrate of the antenna is used for the Teflon dielectric material having relative permittivity of 2.1 and a height of $0.6 \mathrm{~mm}$. The cavity wall thickness of 0.2 $\mathrm{mm}$ with FR-4_epoxy and metal cap thickness of $2 \mathrm{~mm}$ are considered in design. The required antenna bandwidth, including $\mathrm{Tx}$ and $\mathrm{Rx}$, is from 2.4 to $7.36 \mathrm{GHz}$. The Tx band is from 2.4 to $2.48 \mathrm{GHz}$, and the Rx band is from 4.84 to $4.92 \mathrm{GHz}$ for the $2 \mathrm{nd}$ harmonic frequency and from 7.28 to $7.36 \mathrm{GHz}$ for the 3 rd harmonic frequency.

Fig. 2(a) shows the simulated return loss of antenna

Manuscript received April 12, 2013 ; Revised August 12, 2013 ; Accepted August 19, 2013. (ID No. 20130412-013J)

Department of Radio Communication Engineering, Korea Maritime University, Busan, Korea.

*Corresponding Author : Kyeong-Sik Min (e-mail : ksmin@hhu.ac.kr)

This is an Open-Access article distributed under the terms of the Creative Commons Attribution Non-Commercial License (http://creativecommons.org/licenses/ by-nc/3.0) which permits unrestricted non-commercial use, distribution, and reproduction in any medium, provided the original work is properly cited. 


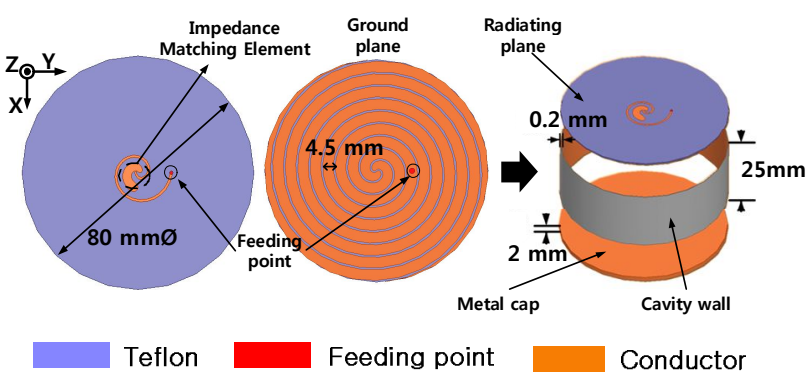

Fig. 1. Antenna configuration with the conventional 4.5-turn spiral slit structure on ground plane.

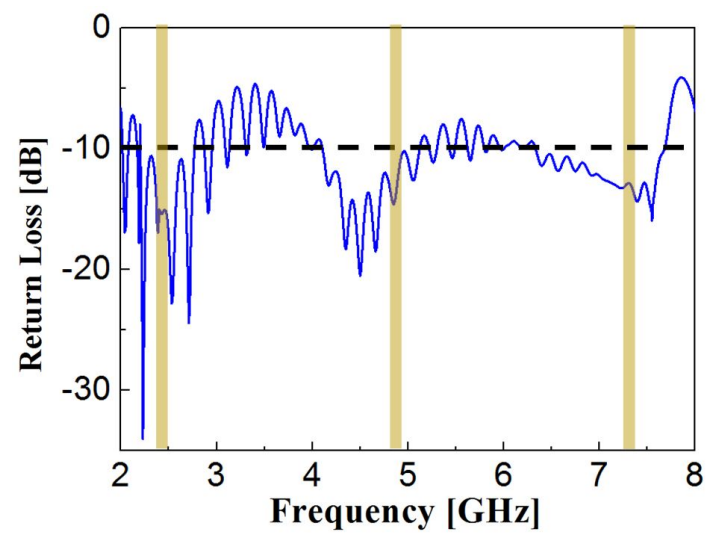

(a)

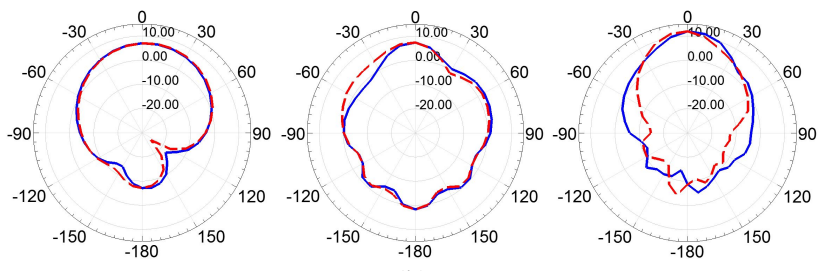

(b)

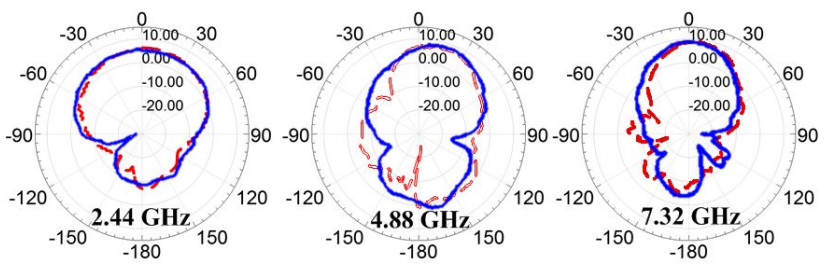

(c)

Fig. 2. Simulated and measured results of antenna structure in Fig. 1 (solid line, Y-Z plane; dotted line, $\mathrm{X}-\mathrm{Z}$ plane). (a) simulated return loss, (b) simulated gain radiation pattern, and (c) measured gain radiation pattern.

structure shown in Fig. 1. The return loss is $-10 \mathrm{~dB}$ lower at the interested 3 bands. Fig. 2(b) and (c) show the simulated and measured gain radiation pattern of the antenna structure shown in Fig. 1.

Table 1 shows the simulated gain at the interested center frequency, where $\theta=0^{\circ}$, and $\phi=0^{\circ}$.
Table 1. Simulated gain of antenna structure in Fig. 1

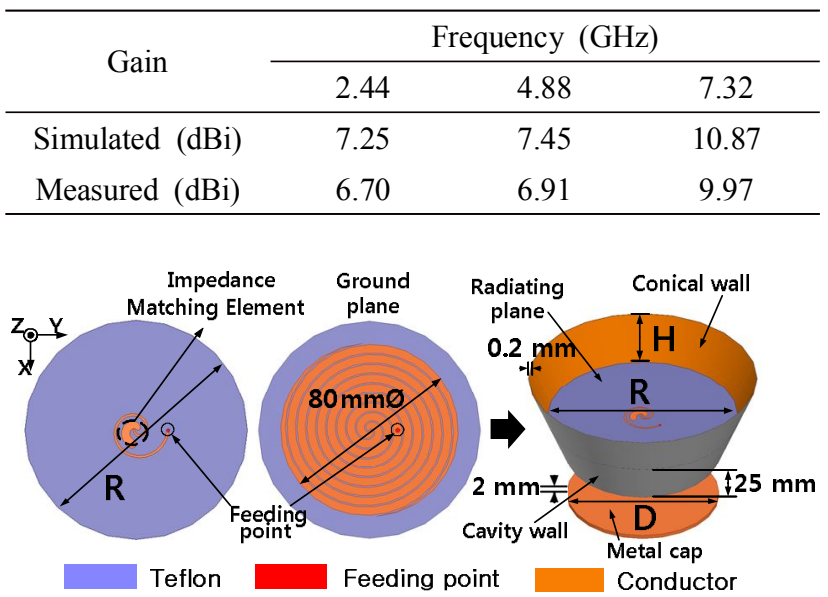

Fig. 3. Spiral antenna composed of a conical wall structure.

In order to increase gain of conventional antenna structure in Fig. 1, authors proposed the improved cavity wall with the added conical wall as shown in Fig. 3. In addition, an optimum conical wall was designed by studying the parameters of conical's radius $(R)$, metal cap diameter $(D)$ and conical's height $(H)$, and simulation with a commercial tool.

Fig. 3 shows the spiral antenna composed of a conical wall structure. The diameter of the Archimedean spiral slit on the ground plane is $80 \mathrm{~mm} \phi$. The cavity wall thickness with FR-4_epoxy and the metal cap thickness are $0.2 \mathrm{~mm}$ and $2.0 \mathrm{~mm}$, respectively, as shown in Fig. 1. The cavity wall height between the metal cap and the radiating plane is the same height of $25 \mathrm{~mm}$ as shown in Fig. 1.

The symbol $R$ shown in Fig. 3 is the diameter of the dielectric material. Changing the height and diameter of conical wall also changes the size of $R$. Thus, the conical wall is very important parameter to study with respect to the variation of $R$. Fig. 4(a) and (b) show the simulated return loss and gain characteristics when $R$ is varied. The variation of $R$ means that each spiral slit length on the radiating plane and the ground plane is constant, and only the diameter size of dielectric material is changed. In the simulation, $D$ and $\mathrm{H}$ from the radiating plane are given by $80 \mathrm{~mm} \phi$ and $0 \mathrm{~mm}$, respectively.

The simulated return loss shown in Fig. 4(a) is still $-10 \mathrm{~dB}$ lower at the interested 3 bands. In Fig. 4(b), the simulated gains of the transmitting and the 2 nd harmonic frequency are increased with the increase of $R$. However, the gain simulated at $7.32 \mathrm{GHz}$ of the $3 \mathrm{rd}$ harmonic frequency shows the maximum value of 12.5 $\mathrm{dBi}$, when $R$ is $100 \mathrm{~mm} \phi$.

Fig. 5 shows the spiral antenna cross-section compo- 

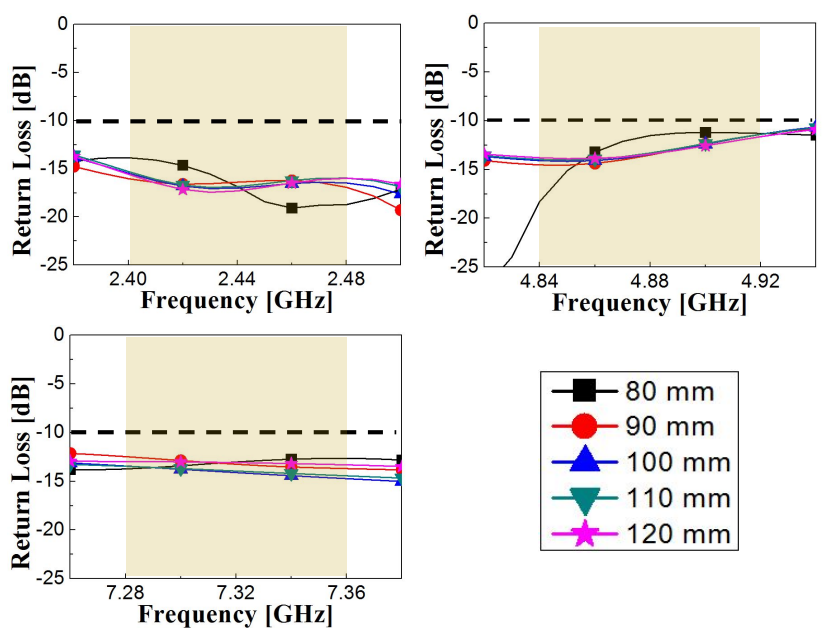

(a)

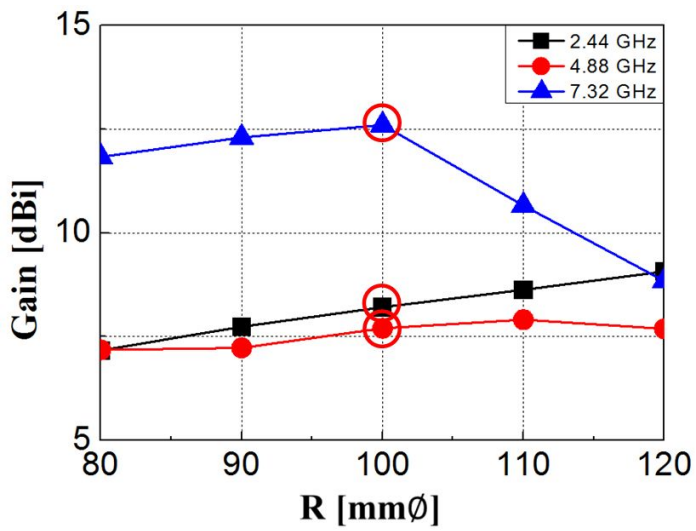

(b)

Fig. 4. Simulated return loss by variation of conical radius $(R)$ : (a) simulated return ross and (b) simulated gain.

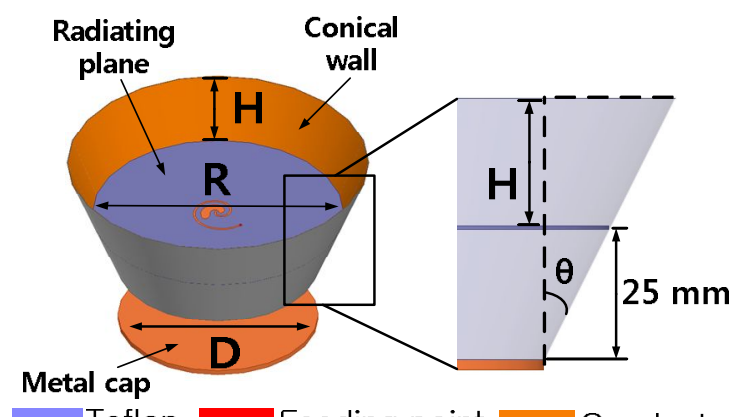

Fig. 5. Spiral antenna cross-section of conical wall structure.

sed of a conical wall structure. When $R$ is changed, degree of conical wall is also changed. The angle of conical wall had a critical effect on the increment of gain. When $R$ was $80,90,100,110$, and $120 \mathrm{~mm} \phi$, the angle between metal cap and conical wall is $0^{\circ}, 11.31^{\circ}$, $21.8^{\circ}, 30.96^{\circ}$, and $38.66^{\circ}$, respectively. The simulated ga-
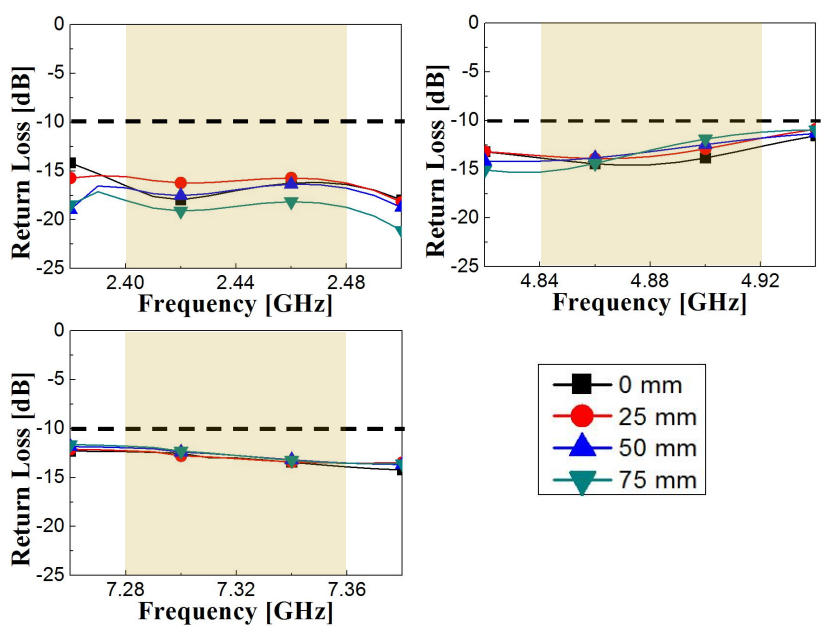

(a)

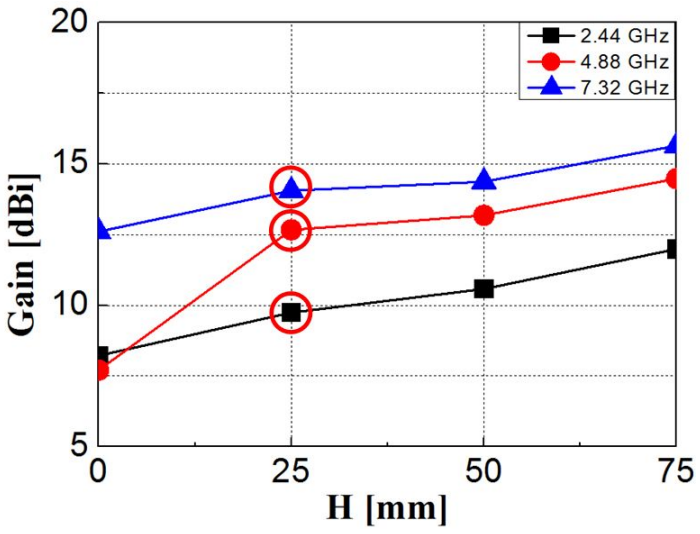

(b)

Fig. 6. Simulated result by variation of conical wall height $(H)$ : (a) simulated retun loss and (b) simulated gain.

in of the 3rd harmonic frequency are decreased above the $100 \mathrm{~mm} \phi$. Because short wavelength of 3rd harmonic frequency is affected by variation of $R$.

Thus, the optimum parameter value of $R$ is selected as $100 \mathrm{~mm} \phi$ by simulation results.

Fig. 6(a) and (b) show the simulated return loss and gain characteristics by variation of the conical wall height from the radiating plane. The values of $R$ and $D$ are $100 \mathrm{~mm} \phi$ and $80 \mathrm{~mm}$, respectively.

The return loss is still $-10 \mathrm{~dB}$ lower at the interested 3 bands, even though $\mathrm{H}$ is changed. Fig. 6(b) shows the simulated gain by variation of $H$. When $H$ is increased, the gain is steadily increased. The conical wall height is operated as a horn antenna length; therefore, $H$ plays a decisive role in gain control. When $H$ is higher, the gain is theoretically more increased, as shown in Fig. 6(b). increasing $H$ realizes strong directivity, where $\theta=0^{\circ}$, and $\phi=0^{\circ}$.

Fig. 7 shows the simulated radiation pattern by variation of $\mathrm{H}$. The difference in the beam width with a co- 


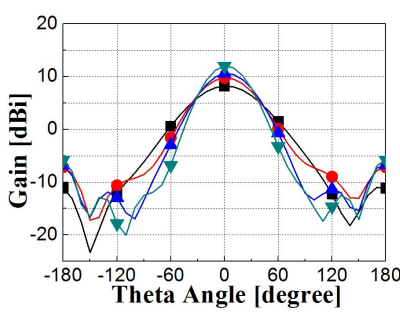

(a) $2.44 \mathrm{GHz}$

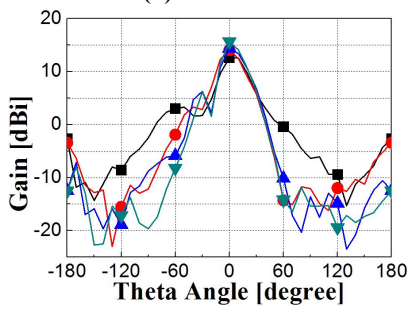

(c) $7.32 \mathrm{GHz}$

(a)

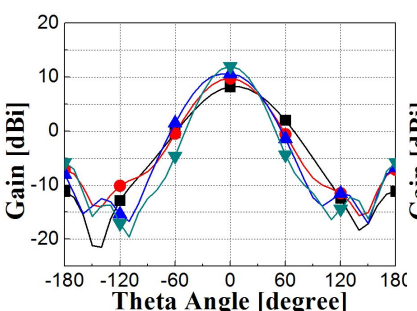

(a) $2.44 \mathrm{GHz}$

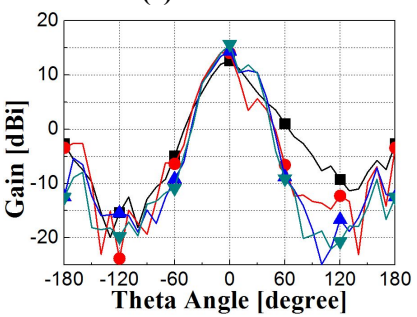

(c) $7.32 \mathrm{GH}$

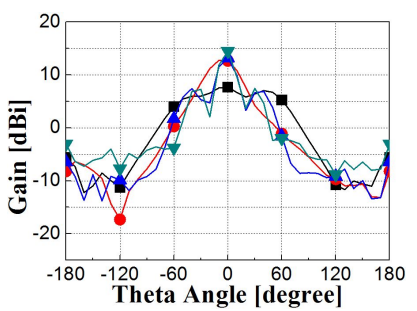

(b) $4.88 \mathrm{GHz}$
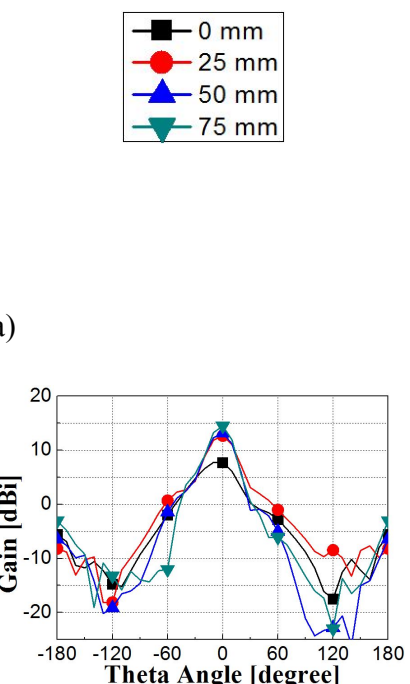

(b) $4.88 \mathrm{GHz}$

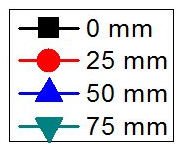

(b)

Fig. 7. Radiation pattern by variation of conical wall height $(H)$ : (a) simulated gain pattern $(\mathrm{Y}-\mathrm{Z})$ and $(\mathrm{b})$ simulated gain pattern $(\mathrm{X}-\mathrm{Z})$.

nical wall height is not very critical, so that even though gain depends on $H, H$ is considered $25 \mathrm{~mm}$ for practical use.

Fig. 8(a) shows the simulated return loss characteristics by variation of the metal cap diameter $D$. In the simulation, the optimized parameters of $R$ and $H$ are fixed at $100 \mathrm{~mm} \phi$ and $25 \mathrm{~mm}$. Even though $D$ is changed, the return loss is still $-10 \mathrm{~dB}$ lower. Fig. 8(b) shows the simulated gain by variation of $D$. The gain shows the maximum value at the 2 nd and the 3 rd frequency, when $D$ equals $70 \mathrm{~mm} \phi$.

Fig. 9 shows the simulated results and with and without a conical wall for 4.5-turn spiral slit on the ground plane. The simulated optimum parameter values of $R, H$, and $D$ are $100 \mathrm{~mm} \phi, 25 \mathrm{~mm}$ and $70 \mathrm{~mm} \phi$, respectively.
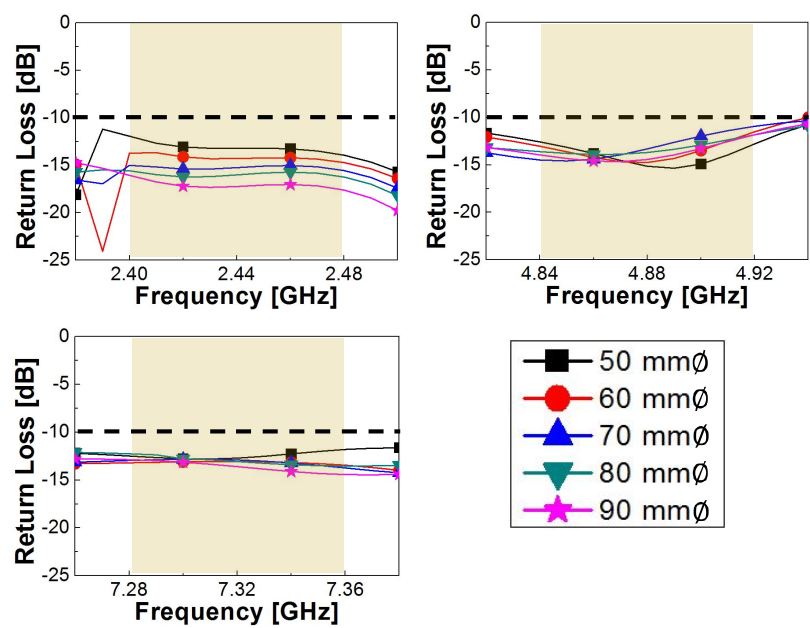

(a)

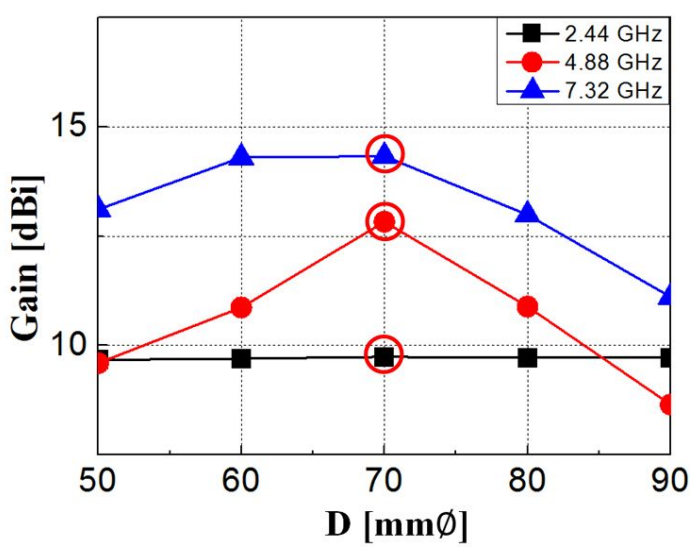

(b)

Fig. 8. Simulated results by variation of metal cap diameter (D): (a) simulated return loss and (b) simulated gain.

Fig. 9(a) and (b) show a comparison of the simulated return loss and axial ratio with and without the conical wall, respectively. The return loss value and also the axial ratio value are almost the same, which means that the return loss characteristics and the axial ratio characteristics are not particularly affected by the existence of the conical wall. Furthermore, a comparison of Table 1 and Fig. 8(b) confirmed that the gain of the spiral antenna could be easily controlled by the conical wall parameters such as $R, H$, and $D$. The simulated gain of the spiral antenna with an added conical wall at 2.44 $\mathrm{GHz}$ of $\mathrm{Tx}$ center frequency appears $9.74 \mathrm{dBi}$ and it is $2.5 \mathrm{dBi}$ higher than the one at $2.44 \mathrm{GHz}$ of Table 1. The gains at the 2nd and the 3rd harmonic frequency of $\mathrm{Rx}$ are higher by about 5.4 and $3.5 \mathrm{dBi}$, respectively, when compared to the conventional one seen in Table 1.

However, even though the gain is markedly improved by the added conical wall, the axial ratio at the Tx band remains poor, at an average of $7.5 \mathrm{~dB}$ as shown in Fig. 


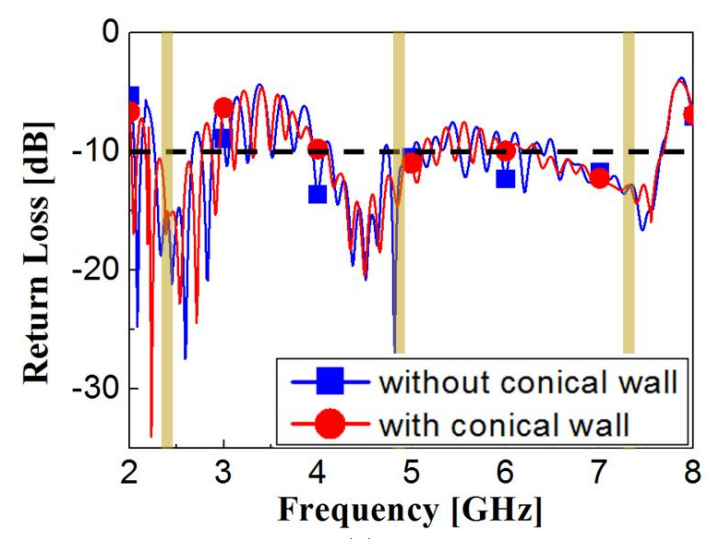

(a)
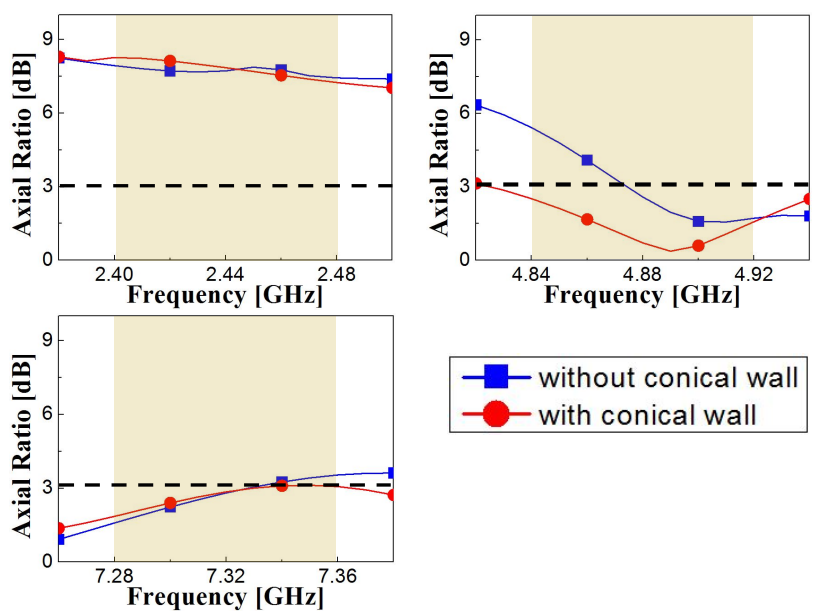

(b)

Fig. 9. Comparison of simulated result obtained with and without a conical wall for 4.5-turn spiral slit on ground plane: (a) simulated return loss and (b) simulated axial radio.

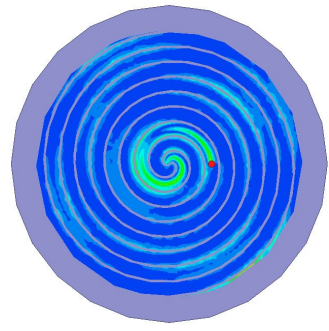

(a)

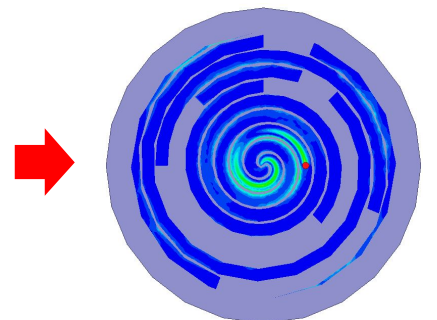

(b)
Fig. 10. Electric current distribution of an archimedean slit structure located on ground plane at $2.44 \mathrm{GHz}$ : (a) 4.5-turn and (b) optimized.

9(b). This is caused by the current reflected from the metal cap. The solution to the poor axial ratio problem was sought by examining the current distribution of archimedean slit on the ground plane at $2.44 \mathrm{GHz}$.

Fig. 10 shows the comparison of the electric current distribution of the archimedean slit structure located on the ground plane at $2.44 \mathrm{GHz}$ [5]. The electric current

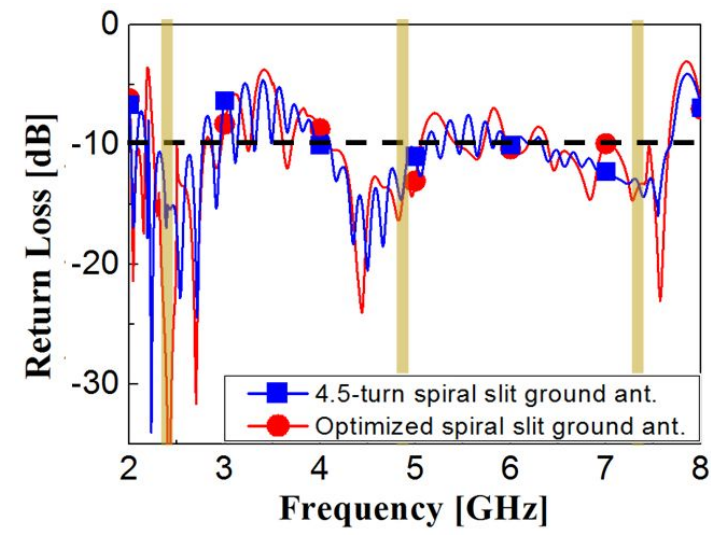

(a)
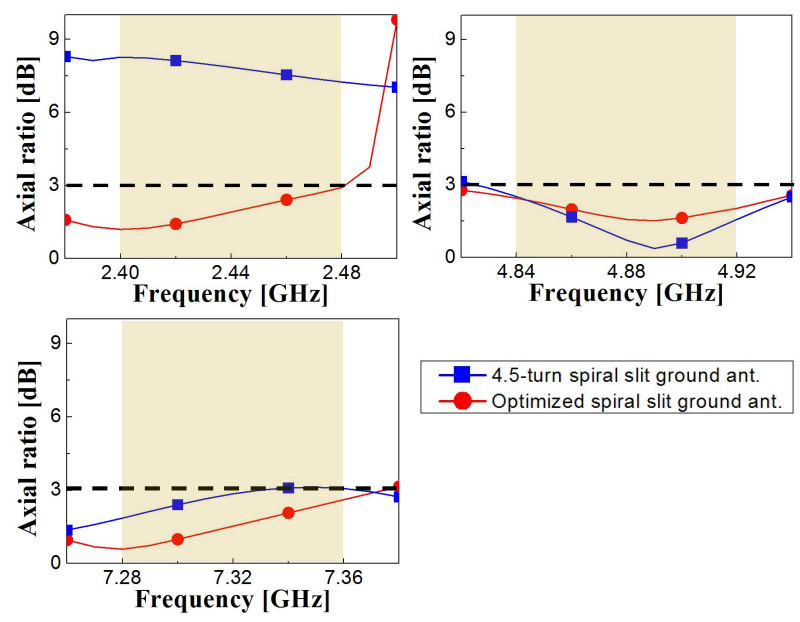

-4.5-turn spiral slit ground ant. - Optimized spiral slit ground ant.

(b)

Fig. 11. Comparison of simulated results for the 4.5-turn and of the optimized spiral slit on ground plane. (a) simulated return loss and (b) simulated axial ratio.

of the conventional 4.5-turn spiral slit structure on the ground plane appears somewhat stronger than the current for the optimized slit structure in Fig. 10(b). However, this is due to the sum of the current with the circular polarization that is radiated in the opposite direction by current reflected from metal cap, as shown in Fig. 1.

The reason for the current generation with reverse polarization is that the quarter wavelength of $2.44 \mathrm{GHz}$ is longer than the $25 \mathrm{~mm}$ cavity wall height. The conventional 4.5-turn spiral slit on the ground plane is newly designed, as shown in Fig. 10(b), and proposed in [5]. The gain of the optimized slit shown in Fig. 10(b) was almost unchanged when compared with the conventional antenna in Fig. 1 [5]. This means that the spiral slit structure on the ground plane was optimized by controlling the electric current distribution at $2.44 \mathrm{GHz}$, and the gain value was constantly maintained even though the physical conductor surface size was reduced by removal of the slit.

Fig. 11 shows the simulated return loss characteristics 
of the antenna with respect to two kinds of archimedean slits on the ground plane as shown in Fig. 10(a) and (b). The simulated return loss of the 4.5-turn and the optimized spiral slit with the conical wall shows very similar results, and it is maintained $-10 \mathrm{~dB}$ lower at the interested 3 bands. This means that the return loss is independent of the spiral slit structure on the ground plane. On the other hand, the axial ratio strongly depends on the spiral slit structure, as shown in Fig. 11(b). The simulated axial ratio at $2.44 \mathrm{GHz}$, as well as at 4.88 and $7.32 \mathrm{GHz}$, is clearly improved by the optimization of the spiral slit structure on the ground plane. The axial ratio is $3 \mathrm{~dB}$ lower at the interested 3 bands.

\section{Measurement}

The effectiveness of the proposed antenna was verified by fabricating the novel antenna with an optimized slit on the ground plane and with the added conical wall, as shown in Fig. 12.

Fig. 13(a) shows the comparison between the simulated and the measured return loss of the designed and fabricated antenna, respectively. The measured return loss shows reasonable agreement with the simulated one, even though it is slightly different. Fig. 13(b) shows the comparison of the simulated and the measured axial ratio. The simulated axial ratio and the measured axial ratio show good agreement and the ratio is maintained at $3 \mathrm{~dB}$ lower at the interested band.

Fig. 14 shows the comparison between the simulated and the measured 2-D gain patterns at 2.44, 4.88, and $7.32 \mathrm{GHz}$.

The solid and dotted lines indicate the main E-field polarization of the $\mathrm{X}-\mathrm{Z}$ plane and of the $\mathrm{Y}-\mathrm{Z}$ plane, respectively. The measured E-field gain patterns showed very fine agreement with the simulation results, as shown in Fig. 14.

Table 2 shows the gain comparison of the spiral antenna with the conventional 4.5-turn spiral slit and the newly designed optimized slit on ground plane, with and without the conical wall antenna. As seen in Fig 8(b), the gain is controlled by with and without conical wall.

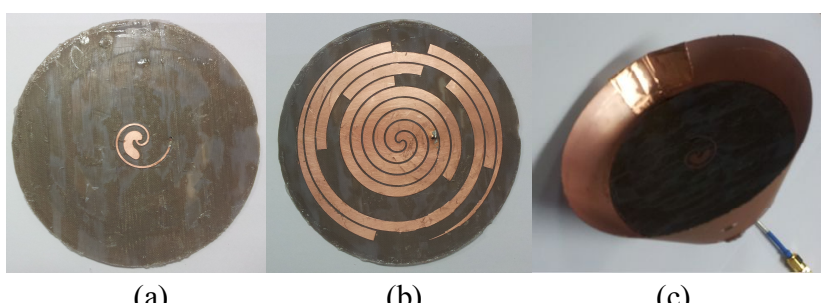

(a)

(b)

(c)

Fig. 12. Photograph of a fabricated antenna: (a) radiating plane, (b) ground plane, and (c) conical wall.

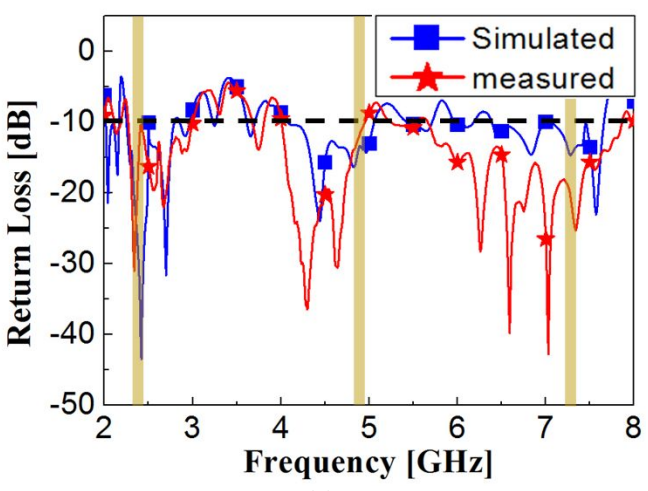

(a)
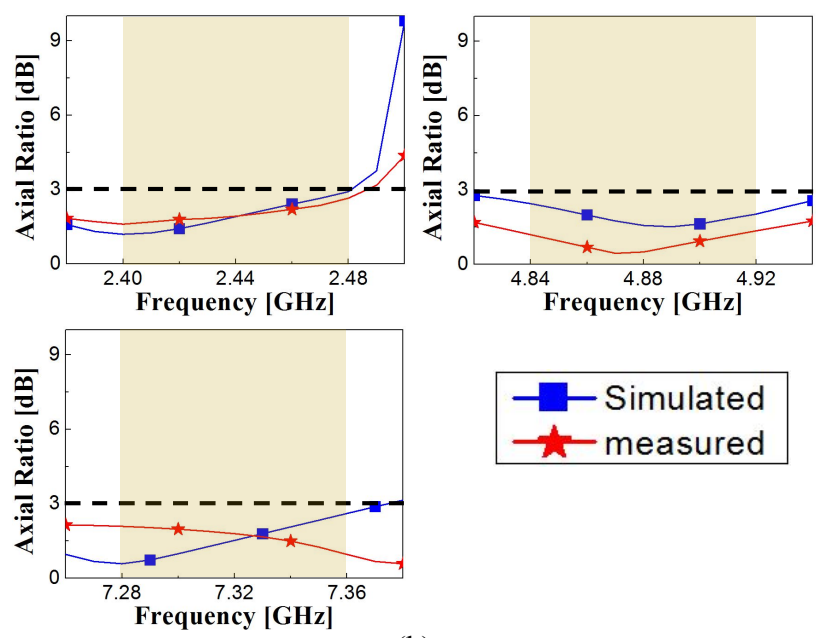

(b)

Fig. 13. Comparison between the simulated and the measured result of a proposed novel antenna: (a) return loss and (b) axial ratio.

Table 2. Gain comparison of the spiral antenna (unit: $\mathrm{dBi}$ )

\begin{tabular}{llccc}
\hline \multirow{2}{*}{$\begin{array}{l}\text { Spiral slit on } \\
\text { ground plane }\end{array}$} & \multirow{2}{*}{ Conical wall } & \multicolumn{3}{c}{ Frequency $(\mathrm{GHz})$} \\
\cline { 3 - 5 } & & 2.44 & 4.88 & 7.32 \\
\hline \multirow{2}{*}{ 4.5-turn } & Without (Sim.) & 7.25 & 7.45 & 10.87 \\
& With (Sim.) & 9.74 & 12.83 & 14.33 \\
\multirow{2}{*}{ Optimized } & With (Sim.) & 9.74 & 12.67 & 14.05 \\
& With (Mea.) & 9.71 & 12.59 & 14.02 \\
\hline
\end{tabular}

Table 3. Axial ratio comparison of the spiral antenna

(unit: $\mathrm{dB}$ )

\begin{tabular}{lllll}
\hline \multirow{2}{*}{$\begin{array}{l}\text { Spiral slit on } \\
\text { ground plane }\end{array}$} & \multirow{2}{*}{ Conical wall } & \multicolumn{3}{c}{ Frequency (GHz) } \\
\cline { 3 - 5 } & & 2.44 & 4.88 & 7.32 \\
\hline \multirow{2}{*}{4.5 -turn } & Without (Sim.) & 7.71 & 2.59 & 2.81 \\
& With (Sim.) & 7.85 & 0.71 & 2.85 \\
\multirow{3}{*}{ Optimized } & With (Sim.) & 1.90 & 1.57 & 1.52 \\
& With (Mea.) & 1.92 & 0.50 & 1.79 \\
\hline
\end{tabular}

For example, the gain of the spiral antenna with the conical wall and with the 4.5-turn spiral slit on the 


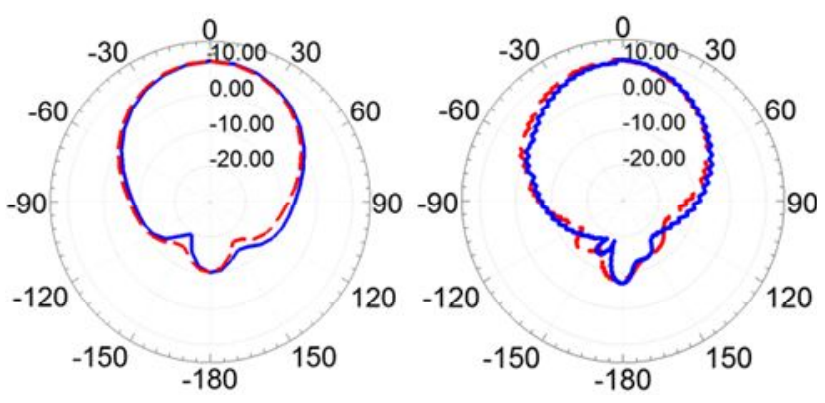

(a)

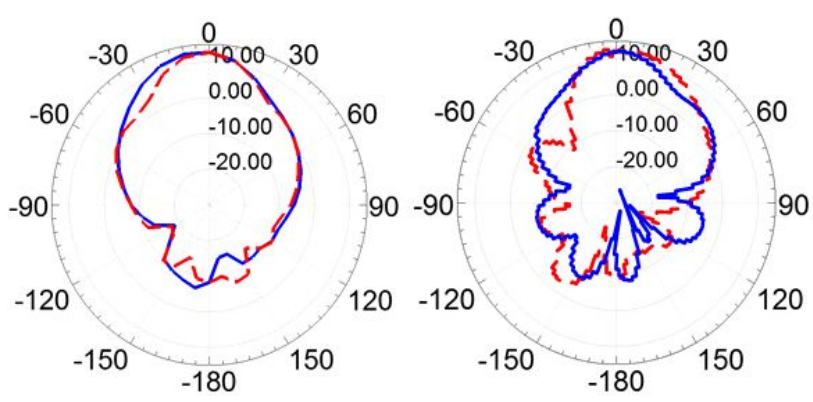

(b)

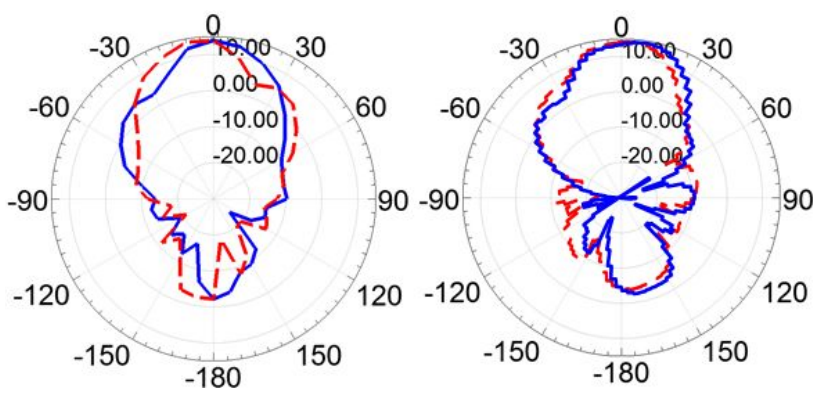

(c)

Fig. 14. Simulated and measured gain patterns (solid line, $\mathrm{Y}-\mathrm{Z}$ plane; dotted line, $\mathrm{X}-\mathrm{Z}$ plane).

ground plane is almost the same value when compared with the optimized slit antenna gain as shown in Table 2. This means that antenna gain has no relation with slit structure.

Table 3 shows the axial ratio comparison of the spiral antenna. As in Fig 9(b), the axial ratio is improved by the newly designed slit on the ground plane. It is not dependent on conical wall. The quarter wavelength of $2.44 \mathrm{GHz}$ is longer than the height of the cavity wall in Fig. 1; therefore, the axial ratio becomes increasingly worse due to the current with the opposite circular polarization reflected from metal cap. The improvement of the axial ratio is realized by the novel design of the slit on the ground plane.

\section{Conclusion}

This paper proposed a design for a spiral antenna wi- th a conical wall to obtain a high gain. One application of the proposed antenna is the NLJD system. The gain and the axial ratio of spiral antenna were improved by using a conical wall and a newly designed Archimedean slit on the ground plane for a conventional antenna with a circular cavity wall and a conventional 4.5-turn slit. The improved gain of $9.5 \mathrm{dBi}$ above at $2.44 \mathrm{GHz}$ and the good axial ratio of $1.9 \mathrm{~dB}$ lower at the interested band are realized by the added conical wall and the newly designed slit from current distribution control on ground plane, respectively. The measured return loss was $-10 \mathrm{~dB}$ lower at the interested band. The simulated return loss and axial ratio of proposed antenna agreed well with the measured results. The measured E-field gain patterns of the $\mathrm{X}-\mathrm{Z}$ plane as well as the $\mathrm{Y}-\mathrm{Z}$ plane also showed very good agreement with the simulated results.

\section{References}

[1] Audiotel International Limited, "Non-linear junction detector," Australian Patent 2002229931, 2002.

[2] K. Wincza, S. Gruszczynski, and J. Borgosz, "Dualband capacitive feed antenna for nonlinear junction detection device," in Proceedings of the 14th Conference on Microwave Techniques, Prague, Czech Republic, 2008.

[3] M. N. Afsar, Y. Wang, and H. Ding, "A new wideband cavity-backed spiral antenna," in Proceedings of the IEEE Antennas and Propagation Society International Symposium, Boston, MA, 2001, pp. 124127.

[4] J. W. Kim, K. S. Min, I. H. Kim, and C. J. Park, "Triple band spiral antenna for non-linear junction detector," in Proceedings of International Symposium on Antennas and Propagation, Nagoya, Japan, 2012, pp. 802-805.

[5] J. W. Kim and K. S. Min, "Design of broadband spiral antenna for a portable non-linear junction detector system," Journal of Electromagnetic Engineering and Science, vol. 24, no. 1, pp. 36-46, Jan. 2013.

[6] T. Morimoto and S. Kawasaki, "A novel laminated printed spiral antenna for higher gain," in Proceedings of the Asia-Pacific Microwave Conference, Taipei, Taiwan, 2001, pp. 476-479.

[7] H. M. Jeong, S. B. Park, C. W. Kim, O. Sodnomtseren, J. H. Bang, and B. C. Ahn, "A conical-cylindrical monopole antenna," Journal of the Korea Electromagnetic Engineering and Society, vol. 7, no. 3, pp. 138-146, Sep. 2007.

[8] M. Lee, B. A. Kramer, C. C. Chen, and J. L. Volakis, "Distributed lumped loads and lossy transmiss- 
ion line model for wideband spiral antenna miniaturization and characterization," IEEE Transactions on Antennas and Propagation, vol. 55, no. 10, pp. 2671-2678, Oct. 2007.

\section{Jae-Hwan Jeong}

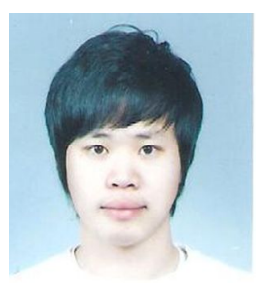

was born in South Korea on June 26, 1987. He received the B.S. degree in Radio Communication Engineering (2012) from Korea Maritime University of Busan. $\mathrm{He}$ is currently working toward a Master's degree in Radio Communication Engineering at Korea Maritime University. His fields of research include spiral antennas and wide band antenna design.

\section{Kyeong-Sik Min}

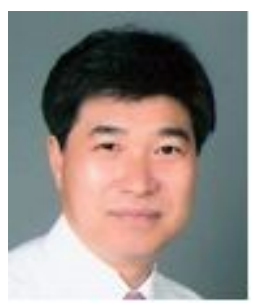

was born in South Korea. He received the B.S. and M.S. degree in the Department of Electronic Communications Engineering from Korea Maritime University, in 1989 and 1991, respectively. He received the Ph.D. degree in Department of Electromagnetic Wave and Electronics Engineering from the Tokyo Institute of Technology in 1996. Currently, he is professor of the Department of Radio Communication Engineering at the Korea Maritime University. His research interests include the design of Spiral antenna, RFID, MDM (Magneto-Dielectric Material), MIMO antenna, and analysis of FDTD (Finite-Difference Time Domain).
[9] T. K. Chen and G. H. Huff, "Stripline-fed archimedean spiral antenna," IEEE Antennas and Wireless Propagation Letters, vol. 10, pp. 346-349, 2011.

\section{In-Hwan Kim}

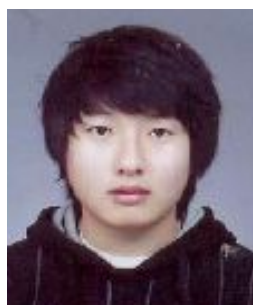

was born in South Korea on March 7, 1987. He received the B.S. degree in Electronic Communication Engineering (2011) from Korea Maritime University of $\mathrm{Bu}-$ san. He is currently working toward a Master's degree in Radio Communication Engineering at Korea Maritime University. His fields of research include UWB antennas and antenna measurement. 